Article

\title{
Performance Evaluation of External Light Shelves by Applying a Prism Sheet
}

\author{
Heangwoo Lee ${ }^{1} \mathbb{C}$ and Janghoo Seo ${ }^{2, *}$ \\ 1 College of Design, Sangmyung University, Cheonan-si 31066, Chungcheongnam-do, Korea; 2hw@smu.ac.kr \\ 2 School of Architecture, Kookmin University, Seoul 02707, Korea \\ * Correspondence: seojh@kookmin.ac.kr; Tel.: +82-2-910-4593
}

Received: 22 August 2020; Accepted: 3 September 2020; Published: 4 September 2020

\begin{abstract}
To address the increased use of lighting energy in the building sector, research on the use of light shelves has been increasing. Previous studies have focused on applying operating techniques to improve daylighting performance, which reduces the economic efficiency of light shelves and the building energy savings. This study proposes the use of prism sheets to improve the performance of light shelves, a concept which was validated by evaluating the performance related to saving building energy and improving indoor light uniformity through a full-scale testbed. This study used an external light shelf with no prism sheet, a window with a prism sheet applied, and a window with both an external light shelf and prism sheet applied as Case 1, Case 2, and Case 3, respectively, and analyzed the illuminance distribution and lighting energy consumption required to maintain the optimal indoor illumination for each case. This study also derived the optimal specifications for each case to save building energy and considered the flow of natural light to analyze the performance evaluation results. The main findings are as follows: (1) the optimal specifications to improve daylighting performance were derived for Case 1, requiring the application of operating techniques; (2) Case 2 was not suitable for saving energy and improving light uniformity when compared to Case 1 ; and (3) Case 3 was effective in saving building energy. In Case 3, even when the light shelf was fixed at $20^{\circ}$ without moving, it saved building energy and improved light uniformity compared to Case 1. However, the prism sheet in Case 3 should be detached during winter to maximize building energy savings.
\end{abstract}

Keywords: external light shelf; prism sheet; performance evaluation; energy saving

\section{Introduction}

Concerns over greenhouse gas (GHG) emissions and global warming are growing as the use of fossil fuels continues to increase due to surges in energy consumption [1]. According to the "2014 Energy Consumption by Sector in the EU-28" Eurostat report the building sector accounted for the highest proportion (38.1\%) of energy consumption, that is, higher than the industrial and transportation sectors. Additionally, according to the "2017 Renewable Energy Data Book" U.S. Energy Information Administration (EIA) report, buildings (residential and commercial combined) accounted for $38.9 \%$ of total energy use [2], highlighting the importance of technology development and research to solve this issue. In particular, the need for research and technology development to solve lighting energy problems is expected to increase gradually, as it accounts for about $9 \%$ of the total energy used in buildings, which is only exceeded by space heating, water heating, and space cooling [3]. Accordingly, a wide variety of studies have been conducted on daylighting and shades, such as light ducts [4], blinds [5-7], and louvers [8-10]. A light shelf is a typical natural daylighting system that introduces external natural light deep into rooms by using the reflector of the light shelf and the surface of the ceiling. Various studies have confirmed the effectiveness of light shelves [11-13]. However, 
conventional light shelves use flat reflectors to introduce external natural light into rooms [14], so the daylighting performance of the light shelf may be reduced depending on external environmental factors, such as the altitude of the sun. Recently, research $[15,16]$ and technologies incorporating operating techniques have been introduced to solve this problem; however, moving light shelves may be unsuitable for saving building energy due to difficulties in maintenance and the need to consume additional energy in their operation [17].

This study proposes the use of prism sheets to solve these problems since they can improve daylighting performance when applied to light shelves by changing the propagation of light through reflection and refraction. The purpose of this study is to obtain basic data for saving building energy by applying prism sheets and validating their performance in improving the daylighting performance of light shelves.

\subsection{Concept of a Light Shelf and Summary of Previous Studies}

As shown in Figure 1, a light shelf is a typical natural daylighting system that is installed on a window to introduce natural light from outside the window deep into the room using the reflector of the light shelf and the surface of the ceiling. Light shelves can save lighting energy by introducing external natural light into rooms and also can resolve unbalanced indoor illumination by blocking excessive natural light from the window. The variables that determine the daylighting performance of light shelves include the width, reflectance, height, and angle of the light shelf, and, as shown in Figure 2, controlling the light-shelf angle makes it easy to cope with external environmental factors. In particular, movable light shelves provide advantages such as the ability to change the shelf's angle, and various studies have been conducted by applying such techniques [12]. However, controlling movable light shelves requires additional energy, so optimal designs need to be applied to deal with related issues. Light shelves are classified into external and internal light shelves depending on the installation location [14]; external light shelves have better daylighting performance than internal light shelves [18], however, there are issues related to damage and maintenance since they are installed on the outside [17].

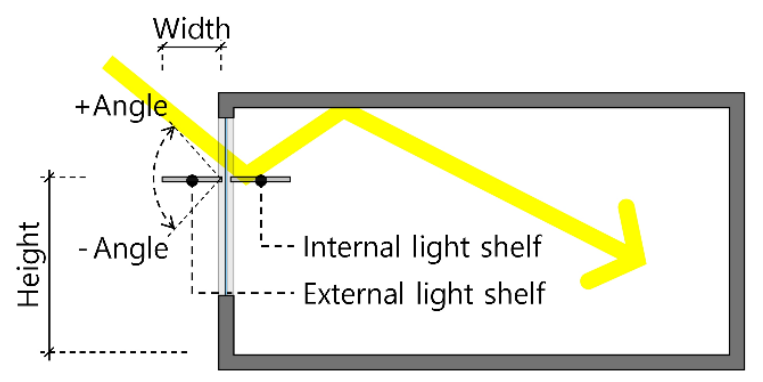

Figure 1. Concept of and variables associated with a light shelf.

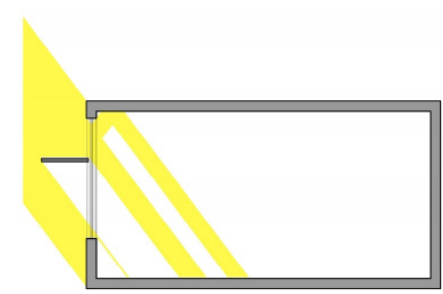

a) Light shelf angle $0^{\circ}$

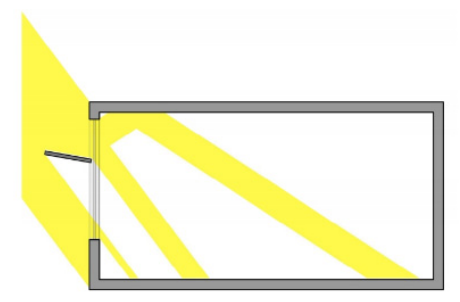

b) Light shelf angle $10^{\circ}$

Figure 2. Differences in the inflow of natural light according to the light-shelf angle.

As shown in Table 1, recent studies related to light shelves [11-16,18-21] have applied advanced technologies such as user recognition and location recognition or have incorporated daylighting and shading systems to improve the daylighting performance. Although the light shelves proposed in 
these studies may contribute to saving lighting energy by maximizing the daylighting performance, they require complex structures or increase the range of motion and therefore have lower economic efficiency than simple conventional light shelves. Movable light shelves also require additional energy to operate, which can reduce building energy-saving efficiency. In this regard, this study aims to improve the daylighting performance of light shelves in a simple way by applying prism sheets while maintaining the structure and shape of conventional light shelves, which is different from previous studies.

Table 1. Summary of previous studies on light shelves.

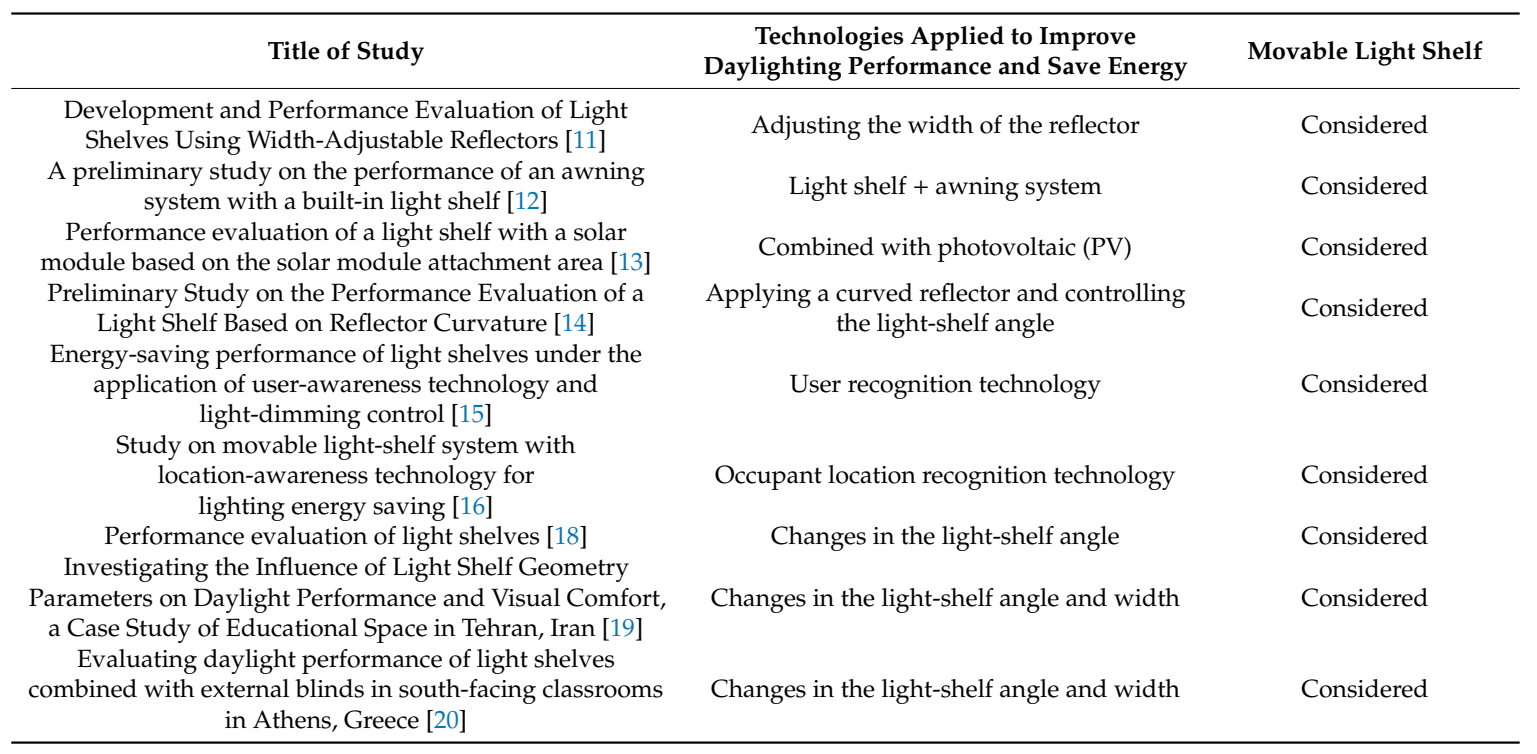

\subsection{The Concept and Principle of Prism Sheets}

This study proposed the use of prism sheets to improve the daylighting performance of external light shelves. A prism sheet forms fine prism structures on a thin polyester film [21]. Prism sheets were developed as optical films to minimize the light loss and increase the brightness of light-emitting materials, and they are used in the display industry as a backlight component for LCDs. Prism sheets are selected and applied according to the characteristics of the product, as they have different condensing, adhesion, and scratch-resistance properties depending on the shape of the tip, the angle of the prism tip, and the surface treatment. As shown in Figure 3, prism sheets have the properties of refraction, regression, and concentration according to the angle of incidence when light passes through the prism sheet. Therefore, the application of prism sheets to daylighting systems such as light shelves may improve the daylighting performance by controlling the amount and depth of natural light entering the room. This study applied condensing prism sheets with specifications as shown in Table 2.

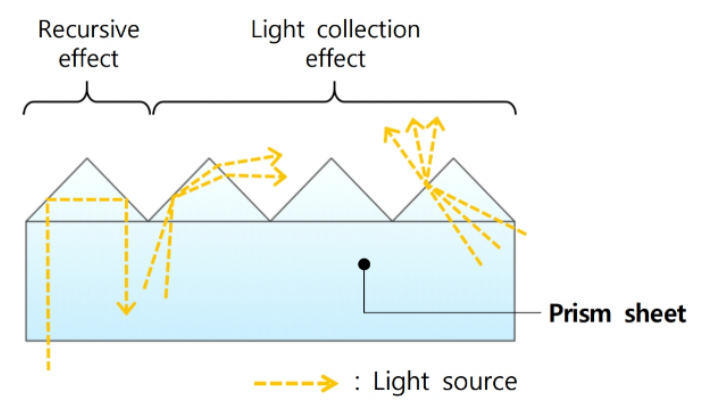

Figure 3. The concept and principle of prism sheets. 
Table 2. Prism sheet specifications.

\begin{tabular}{lccc}
\hline & Specifications & & Specifications \\
\hline Thickness (mm) & $2 \pm 0.2$ & Tip Angle & $45^{\circ}$ \\
Refractive Index & 1.49 & Transmission (\%) & $80-90$ \\
\hline
\end{tabular}

\subsection{Consideration of Optimal Indoor Illumination Standards for Performance Evaluation}

This study calculated the lighting energy consumption with the application of prism sheets and the variables of an external light shelf, considering the optimal indoor illumination standards for this purpose. Optimal indoor illumination standards vary depending on the places where visual tasks are performed, such as offices, hospitals, and houses. These standards also vary according to the type of visual task performed, such as performing visual tasks in a dark atmosphere, performing simple visual tasks occasionally, and performing visual tasks frequently. Table 3 shows the values of optimal indoor illumination standards for various countries. This study set the optimal indoor illumination to $500 \mathrm{~lx}$ for the performance evaluation, and the basis for this is explained as follows. First, the task grade was set to general, and then the overlapping illumination range of 500 to $600 \mathrm{~lx}$ was derived based on the minimum, standard, and maximum allowed illumination in the United States, Japanese, and South Korean standards. However, since $600 \mathrm{~lx}$ was the maximum allowed illumination in the South Korean standard (KS A 3011), this study set the optimal indoor illumination to 500 lx.

Table 3. Indoor illumination standards by country.

\begin{tabular}{cccccc}
\hline Country & $\begin{array}{c}\text { Illumination } \\
\text { Standards }\end{array}$ & Task Grade & $\begin{array}{c}\text { Minimum } \\
\text { Allowed } \\
\text { Illumination (lx) }\end{array}$ & $\begin{array}{c}\text { Standard } \\
\text { Allowed } \\
\text { Illumination (lx) }\end{array}$ & $\begin{array}{c}\text { Maximum } \\
\text { Allowed } \\
\text { Illumination (lx) }\end{array}$ \\
\hline \multirow{3}{*}{ USA } & \multirow{3}{*}{ IES [22] } & Difficult & 1000 & 1500 & 2000 \\
& & General & 500 & 750 & 1000 \\
\multirow{3}{*}{ Japan } & Simple & 200 & 300 & 500 \\
\hline \multirow{3}{*}{ South Korea } & KS Z110 [23] & Difficult & 750 & 1000 & 1500 \\
& & General & 300 & 500 & 750 \\
& & Simple & 150 & 200 & 300 \\
\hline
\end{tabular}

\section{Method}

\subsection{Setting the Variables for Performance Evaluation}

This study proposes the use of prism sheets as a way to improve the daylighting performance of external light shelves, and so the manner in which the prism sheet is applied to the light shelf becomes an important factor for the performance evaluation. Table 4 shows three cases according to how the prism sheet was applied, and the details of these cases are given as follows: Case 1 uses an external light shelf with no prism sheet applied, which is similar to conventional light shelves. The variables of the light shelf were set as shown in Table 5 based on related research [15], and the height of the light shelf was set to $1.8 \mathrm{~m}$ in consideration of the occupants' eye level to maintain window view. Case 2 uses a prism sheet attached to the glass surface of the window without installing a light shelf. As discussed in Section 1.2, prism sheets may have similar effects to light shelves because they refract light; therefore, this study added an independent case to evaluate the performance of a prism sheet. As shown in Figure 4, the prism sheet was attached to the glass surface of the window $1.8 \mathrm{~m}$ above the floor in consideration of the occupants' eye level. Case 3 applies both the light shelf and the prism sheet. The prism sheet can be attached to the reflector or the glass surface of the window in Case 3 . However, when it is attached to the reflector, external natural light may enter indoors by refraction in 
the prism sheet and reflection from the light shelf. Additionally, external natural light will undergo a total of three refraction and reflection processes (refraction by the prism sheet, reflection by the reflector, and refraction by the prism sheet), so only a small amount of light will enter the room, making it unsuitable for improving daylighting performance. Therefore, this study only considered the method of attaching the prism sheet to the glass surface on which the light beam is installed in Case 3 for the performance evaluation. In Case 3, the prism sheet was attached in the same position as in Case 2 (on the glass surface of the window $1.8 \mathrm{~m}$ above the floor).

Table 4. Light shelf variables used for performance evaluation.

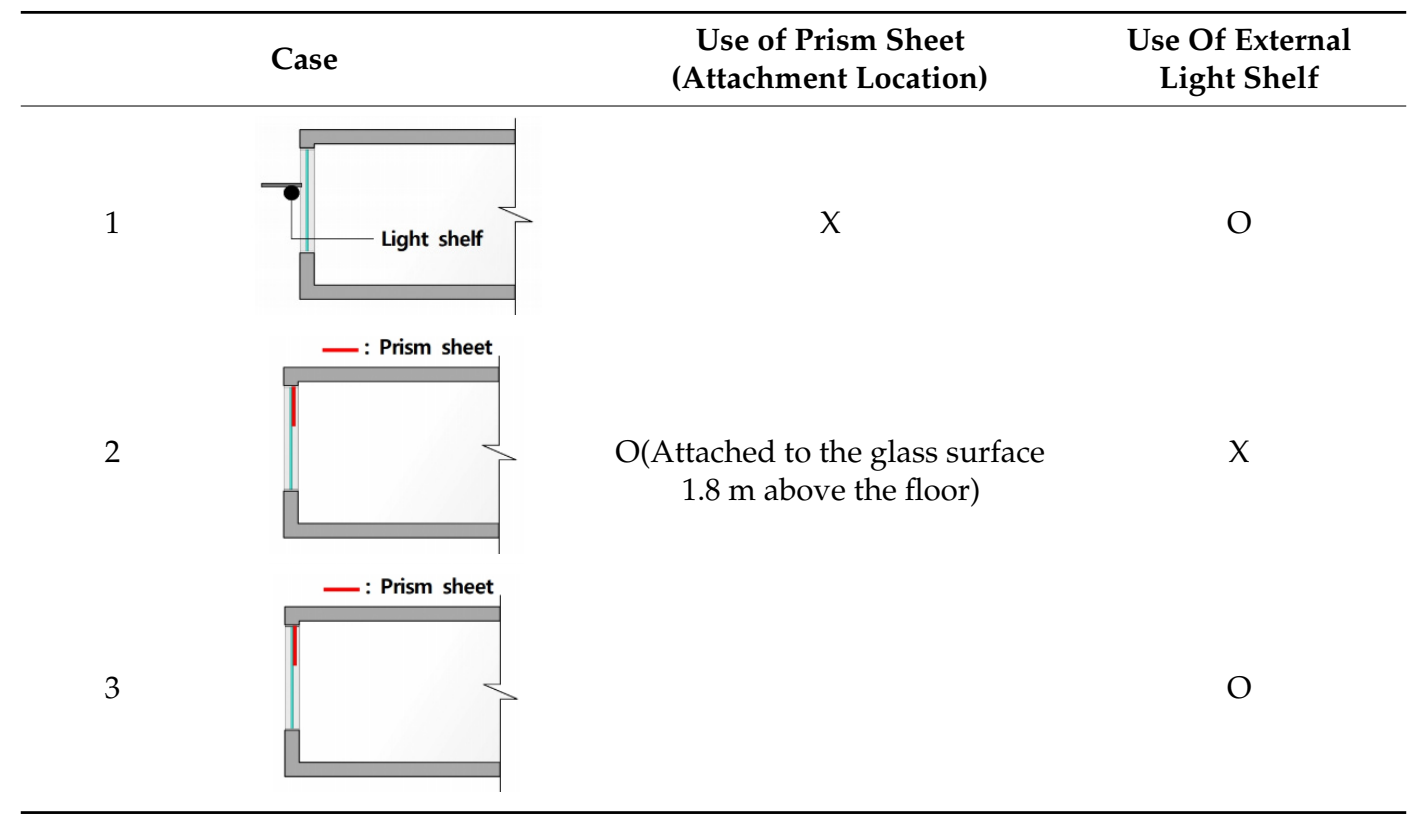

Table 5. Performance evaluation variables of light shelf with curvature.

\begin{tabular}{cccc}
\hline Variable & Range & Variable & Range \\
\hline Height & $1.8 \mathrm{~m}$ & Width & $0.6 \mathrm{~m}$ \\
Reflectance & $85 \%$ (specular reflection film) & Angle & $-10,0,10,20$, and $30^{\circ}$ \\
\hline
\end{tabular}

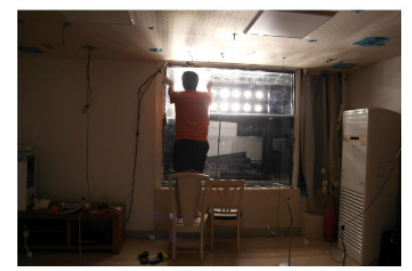

a) Attaching the prism sheet to the glass surface of the window

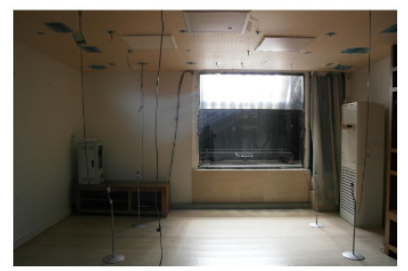

b) Case 2 performance evaluation during summer

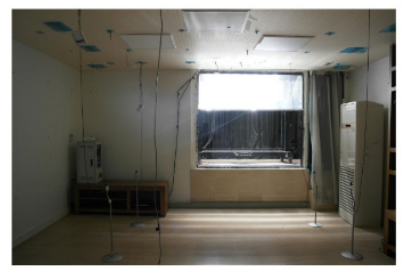

c) Case 3 (light shelf angle $30^{\circ}$ ) performance evaluation during summer

Figure 4. Images showing the attachment of the prism sheet and performance evaluation.

\subsection{Environmental Setting of Performance Evaluation}

For this study, a full-scale testbed was built based on a related study [25] as shown in Table 6, and the details are given as follows: The size of the testbed was $4.9 \mathrm{~m} \times 6.6 \mathrm{~m} \times 2.5 \mathrm{~m}$, and the reflectance was set to $86 \%, 46 \%$, and $25 \%$ for the ceiling, wall, and floor, respectively. The size of the window where the light shelf was installed was $1.9 \mathrm{~m} \times 1.7 \mathrm{~m}$, and the transmittance of the glass was $80 \%$. Four LED-type lights with eight-level dimming control were installed according to the IES four-point method [21] to derive the amount of lighting energy used to maintain the optimal indoor illumination. Figure 5 shows the light distribution curve and the conical illuminance of the 
lighting that was used to evaluate the performance. An artificial solar irradiation apparatus was also installed outside the window where the light shelf was installed to evaluate the performance under various external environments. As shown in Figure 6, the artificial solar irradiation apparatus enabled us to simulate the sun by controlling the intensity, height, and angle of the artificial light source. This Grade-A apparatus ensured measurement uniformity in accordance with ASTM E927-85 [25], so it was able to obtain valid results between performance evaluations. However, the mechanical characteristics of this apparatus meant that it could only be used to evaluate the performance when the sun was facing south since it was impossible to simulate the solar azimuth. As shown in Figure 7, eight illuminance sensors (precision: $\pm 3 \%$ ) were installed to collect the illuminance information of the indoor space. Finally, an energy monitoring system was used to monitor the energy used by the lighting devices.

Table 6. Overview of testbed.

\begin{tabular}{|c|c|}
\hline \multicolumn{2}{|r|}{ Room size and reflexibility } \\
\hline Size & $4.9 \mathrm{~m}(\mathrm{w}) \times 6.6 \mathrm{~m}(\mathrm{D}) \times 2.5 \mathrm{~m}(\mathrm{H})$ \\
\hline Reflexibility & Ceiling $86 \%$, Wall $46 \%$, Floor $25 \%$ \\
\hline \multicolumn{2}{|r|}{ Window size and material } \\
\hline Size/Type & $1.9 \mathrm{~m}(\mathrm{~W}) \times 1.7 \mathrm{~m}(\mathrm{H}) /$ Double-glazed $12 \mathrm{~mm}(3 \mathrm{CL}+6 \mathrm{~A}+3 \mathrm{CL})$ \\
\hline Transmissivity & $80 \%$ \\
\hline \multicolumn{2}{|r|}{ Lighting } \\
\hline Type/Dimensions (mm) & Eight-level dimming (LED type) $4 \mathrm{ea} / 600 \times 600$ \\
\hline Dimming range & $10-100 \%$ \\
\hline Energy consumption for phased & $12.3 \mathrm{kWh}$ (Level 1), $18.3 \mathrm{kWh}$ (Level 2), $22.0 \mathrm{kWh}$ (Level 3), $27.7 \mathrm{kWh}$ (Level 4), \\
\hline light dimming & $34.0 \mathrm{kWh}$ (Level 5), $38.5 \mathrm{kWh}$ (Level 6), $42.6 \mathrm{kWh}$ (Level 7), and 50.8 kWh (Level 8) \\
\hline \multicolumn{2}{|r|}{ Illuminance sensor } \\
\hline Sensing element & Silicon photosensor, with filter \\
\hline Detection range/Precision & $0-200,0001 x / \pm 3 \%$ \\
\hline \multicolumn{2}{|r|}{ Artificial solar light radiation apparatus } \\
\hline Precision of solar light radiation & Grade A (according to ASTM E927-85) \\
\hline Range of illumination & $0-80,000 \mathrm{~lx}$ \\
\hline Directions & South aspect \\
\hline \multicolumn{2}{|r|}{ Energy monitoring system } \\
\hline Model/Measurement capacity & SPM-141/Single phase $(220 \mathrm{~V}, 1-50 \mathrm{~A})$ \\
\hline Measurement items & Power/voltage/current, real-time, and accumulated amount \\
\hline Error rate & Within $2.0 \%$ \\
\hline
\end{tabular}

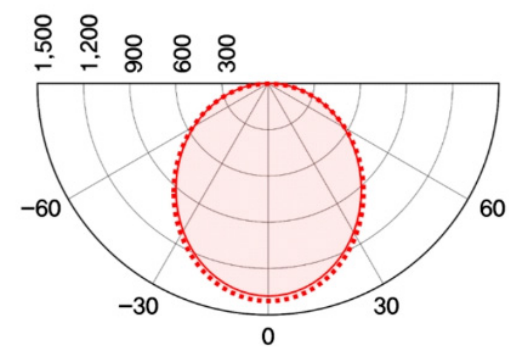

a) Conical illuminance

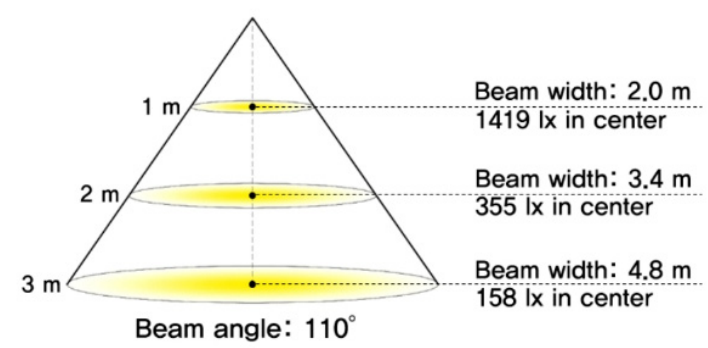

b) Light distribution

Figure 5. Conical illuminance and light distribution of lighting. 


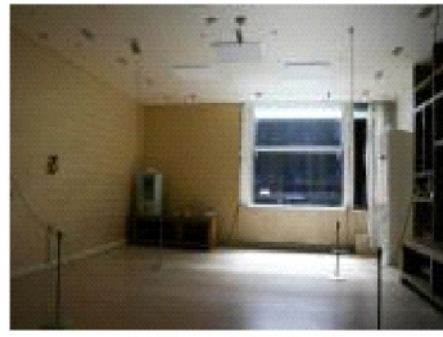

a) View of testbed

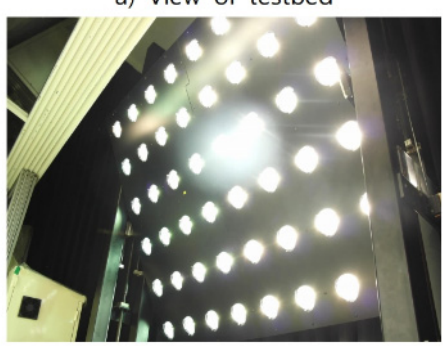

c) Artificial solar irradiation apparatus

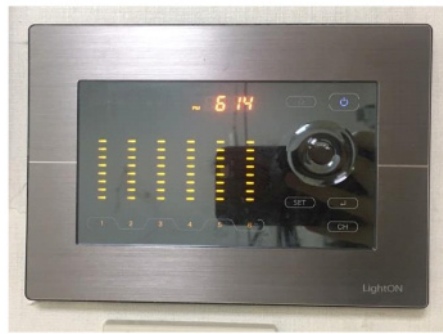

b) Light dimming controller

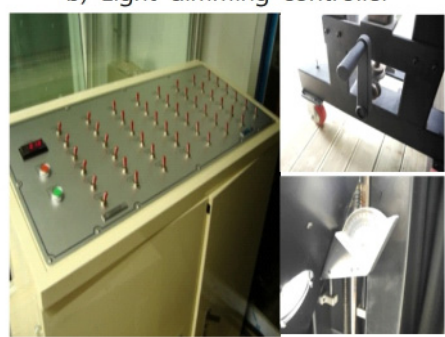

d) Artificial solar irradiation apparatus controller

Figure 6. Conical illuminance and light distribution of lighting.

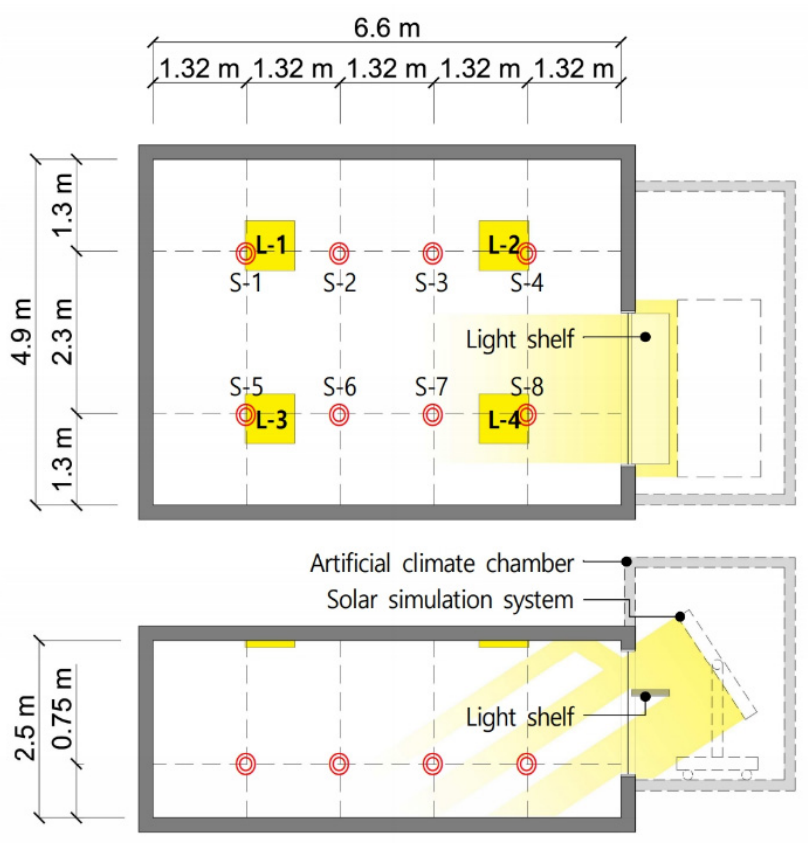

Light-number, O(S-n): Illuminance sensor-number

Figure 7. Conical illuminance and light distribution of lighting.

\subsection{Performance Evaluation Method}

This study evaluated the performance of the external light shelf with a prism sheet using the method detailed in this section.

First, we derived the indoor lighting control level required to maintain the optimal indoor illumination for each of the three cases described in Section 2.1. Lighting control to maintain the optimal indoor illumination was performed according to the following procedure: First, lighting control was performed only when the minimum illuminance measured by the eight illuminance sensors was less than $500 \mathrm{~lx}$; in other words, when the minimum measured illuminance value was $500 \mathrm{~lx}$ or higher, lighting control was not performed, and all of the lights remained off. Therefore, when the minimum value of the illuminance sensors was less than $500 \mathrm{~lx}$, the dimming level of the light next to 
the illuminance sensor with the minimum value was sequentially raised from level 1 to 7 until all of the illuminance sensors reached 500 lx. For example, if illuminance sensor No. 1 had the minimum value (400 lx) among the illuminance sensors, the dimming control of light No. 1, which is closest to illuminance sensor No. 1, was raised sequentially. During the process of raising the dimming level of light No. 1 to level 7, the light control was ended if illuminance sensor No. 1 reached 500 lx; however, if illuminance sensor No. 1 did not reach 500 lx even after light No. 1 was adjusted to level 7, dimming control was performed on light No. 3, which is the next-closest lighting source, until illuminance sensor No. 1 reached 500 lx.

Second, this study derived the lighting energy used in each case based on the lighting control derived above. However, to calculate the lighting energy, this study reflected 15 days in summer, 30 days in mid-season, and 15 days in winter, based on a related study [15], considering only one hour facing south for each day. The solar altitudes for summer, mid-season, and winter were set to 76.5, 53, and $29.5^{\circ}$, respectively, based on the location of Seoul, South Korea.

Third, this study assessed the performance in terms of improving the indoor light environment by deriving the indoor illuminance uniformity for each case. This was based on the fact that the light shelf improves indoor illuminance uniformity by performing both daylighting and shading. Of the various methods that can be applied to derive a uniform illumination environment, this study used the ratio of minimum illumination to mean illuminance.

Fourth, this study visualized the process of natural light entering the room by the prism sheet and external light shelf and used it as a basis for analyzing the performance evaluation results above. AutoCAD was used to visualize the inflow of external natural light into the room by incorporating the reflection of the light shelf and the refractive index of the prism sheet. However, the visualization process was limited to two reflections, namely the reflection by the light shelf and the reflection by the indoor space.

Fifth, this study derived the optimal specifications (limited to the light-shelf angle) for Cases 1 and 3 (i.e., the cases with light shelves) during summer, mid-season, and winter. The optimal specifications for the light shelves reflected the lighting energy consumption and light uniformity but prioritized the former.

Sixth, this study set the energy required to operate the light shelf to $0.120 \mathrm{kWh}$ based on a related study [15], as shown in Table 7, and reflected this to produce more effective research results. The specifications of the motor that was used to operate the light shelf were adjusted in consideration of the size of the light shelf, and the number of operations was set to at least three to find the optimal light-shelf angle according to the external environment.

Table 7. Power draw for light-shelf operation.

\begin{tabular}{cc}
\hline Light-Shelf Control Power Consumption (kWh) & $\begin{array}{r}=\text { AC Motor Operation Power Consumption } \times \\
\text { Operation Time (1 min) } \times \mathbf{3}(\text { time }) \times \mathbf{1}(\mathbf{h}) \times \mathbf{6 0}(\mathrm{day})\end{array}$ \\
\hline 0.120 & $=40 \mathrm{~W} \times(1 / 60) \times 3 \times 1 \times 60$ \\
\hline
\end{tabular}

\section{Performance Evaluation Results and Discussion}

\subsection{Performance Evaluation Results}

This study evaluated the performance of the three cases according to the method above, and results are given in this section.

First, the optimal light-shelf angles for Case 1 (external light shelf with no prism sheet) to save lighting energy and improve the uniformity of indoor illuminance during summer, mid-season, and winter were 30,20 , and $10^{\circ}$, respectively, as shown in Table 8 . Based on these angles, the amount of lighting energy to obtain the optimal indoor illuminance in Case 1 was $3.985 \mathrm{kWh}$. Additionally, as shown in Table 9, the amount of natural light entering the room increases in Case 1 (external light shelf with no prism sheet applied) in the summer due to light-shelf reflection as the light-shelf angle is 
increased from -10 to $30^{\circ}$; however, there is no benefit to be gained by increasing the light-shelf angle during the mid-season and winter.

Second, as shown in Table 9, Case 2 (window with a prism sheet attached $1.8 \mathrm{~m}$ above the floor) shows less change due to refraction when external natural light enters the room due to the high solar altitude during summer. On the other hand, during mid-season and winter, refraction may occur when external natural light enters the room, leading to improved daylighting performance. As a result, the amount of lighting energy used to maintain the optimal indoor illumination (500 lx) in Case 2 was $4.484 \mathrm{kWh}$. This is an $11.1 \%$ increase compared to the amount of lighting energy used based on the optimal angle of Case 1. Additionally, the indoor light uniformity of Case 2 decreased by $19.5 \%$ compared to Case 1, as shown in the performance evaluation results in Table 8, and thus Case 2 was considered to be unsuitable.

Third, the optimal light-shelf angles for Case 3 (with prism sheet) during summer, mid-season, and winter were 20,10 , and $10^{\circ}$, respectively, as shown in Table 8 . Based on this, the amount of lighting energy used to maintain the optimal indoor illuminance was $3.985 \mathrm{kWh}$.

Fourth, as shown in Table 9, external light shelves reflect natural light from the outside and also block excessive natural light from the window, thus improving the uniformity. Additionally, when a prism sheet is attached to the window, natural light enters deep into the room through refraction, improving the indoor light uniformity. In this regard, Case 3 (light shelf with prism sheet) improved the light uniformity by $4.6 \%$ compared to Case 1 (light shelf with no prism sheet), as shown in the performance evaluation results in Table 8.

Table 8. Performance evaluation results by case (indoor illuminance distribution and lighting power consumption).

\begin{tabular}{|c|c|c|c|c|c|c|c|}
\hline \multirow{2}{*}{ Season } & \multirow{2}{*}{ Case } & \multirow{2}{*}{$\begin{array}{l}\text { Light-Shelf } \\
\text { Angle }\end{array}$} & \multicolumn{2}{|c|}{ Illumination Sensor (lx) } & \multirow{2}{*}{$\begin{array}{l}\text { Uniformity } \\
\text { Factor }\end{array}$} & \multirow{2}{*}{$\begin{array}{l}\text { Lighting Dimming Control: } \\
\text { Light Number (Dimming Level) }\end{array}$} & \multirow{2}{*}{$\begin{array}{l}\text { Lighting Energy } \\
\text { Consumption }(\mathrm{kWh}\end{array}$} \\
\hline & & & Minimum & Average & & & \\
\hline \multirow{10}{*}{ Summer } & \multirow{4}{*}{1} & -10 & 81.8 & 379.5 & 0.216 & $1(8)+3(8)+2(3)$ & 1.855 \\
\hline & & 10 & 92.4 & 404.0 & 0.229 & $1(8)+3(8)+2(2)$ & 1.799 \\
\hline & & 20 & 104.6 & 406.4 & 0.257 & $1(8)+3(8)+2(1)$ & 1.709 \\
\hline & & 30 & 112.9 & 413.1 & 0.273 & $1(8)+3(8)$ & 1.524 \\
\hline & 2 & - & 77.5 & 380.0 & 0.204 & $1(8)+3(8)+2(3)$ & 1.855 \\
\hline & \multirow{5}{*}{3} & -10 & 72.5 & 333.2 & 0.218 & $1(8)+3(8)+2(4)$ & 1.939 \\
\hline & & 0 & 82.1 & 375.6 & 0.219 & $1(8)+3(8)+2(3)$ & 1.855 \\
\hline & & 10 & 102.0 & 390.8 & 0.261 & $1(8)+3(8)+2(1)$ & 1.524 \\
\hline & & 20 & 108.4 & 389.1 & 0.279 & $1(8)+3(8)$ & 1.524 \\
\hline & & 30 & 110.3 & 391.8 & 0.282 & $1(8)+3(8)$ & 1.524 \\
\hline \multirow{11}{*}{$\begin{array}{l}\text { Middle } \\
\text { season }\end{array}$} & \multirow{5}{*}{1} & -10 & 134.2 & 4705.8 & 0.029 & $1(8)+3(4)$ & 2.354 \\
\hline & & 0 & 140.9 & 4712.2 & 0.030 & $1(8)+3(4)$ & 2.354 \\
\hline & & 10 & 149.9 & 4720.9 & 0.032 & $1(8)+3(4)$ & 2.354 \\
\hline & & 20 & 156.7 & 4762.5 & 0.033 & $1(8)+3(3)$ & 2.186 \\
\hline & & 30 & 159.2 & 5064.2 & 0.031 & $1(8)+3(3)$ & 2.186 \\
\hline & 2 & - & 145.2 & 4807.1 & 0.030 & $1(8)+3(4)$ & 2.354 \\
\hline & \multirow{5}{*}{3} & -10 & 142.3 & 4658.7 & 0.031 & $1(8)+3(4)$ & 2.354 \\
\hline & & 0 & 149.4 & 4665.1 & 0.032 & $1(8)+3(4)$ & 2.354 \\
\hline & & 10 & 158.9 & 4673.7 & 0.034 & $1(8)+3(3)$ & 2.186 \\
\hline & & 20 & 160.1 & 4714.9 & 0.034 & $1(8)+3(3)$ & 2.186 \\
\hline & & 30 & 164.2 & 5021.0 & 0.033 & $1(8)+3(3)$ & 2.186 \\
\hline \multirow{11}{*}{ Winter } & \multirow{5}{*}{1} & -10 & 311.4 & 5126.7 & 0.061 & $1(3)$ & 0.331 \\
\hline & & 0 & 321.1 & 5154.4 & 0.062 & $1(2)$ & 0.275 \\
\hline & & 10 & 336.7 & 5233.5 & 0.064 & $1(2)$ & 0.275 \\
\hline & & 20 & 309.7 & 5176.3 & 0.060 & $1(3)$ & 0.331 \\
\hline & & 30 & 301.2 & 5125.3 & 0.059 & $1(3)$ & 0.331 \\
\hline & 2 & - & 320.3 & 5225.3 & 0.061 & $1(2)$ & 0.275 \\
\hline & \multirow{5}{*}{3} & -10 & 315.3 & 5120.5 & 0.062 & $1(2)$ & 0.275 \\
\hline & & 0 & 321.1 & 5190.9 & 0.062 & $1(2)$ & 0.275 \\
\hline & & 10 & 330.9 & 5210.3 & 0.064 & $1(2)$ & 0.275 \\
\hline & & 20 & 314.0 & 5155.2 & 0.061 & $1(2)$ & 0.275 \\
\hline & & 30 & 310.3 & 5126.0 & 0.061 & $1(3)$ & 0.331 \\
\hline
\end{tabular}


Table 9. The inflow of natural light by case and performance evaluation variables.

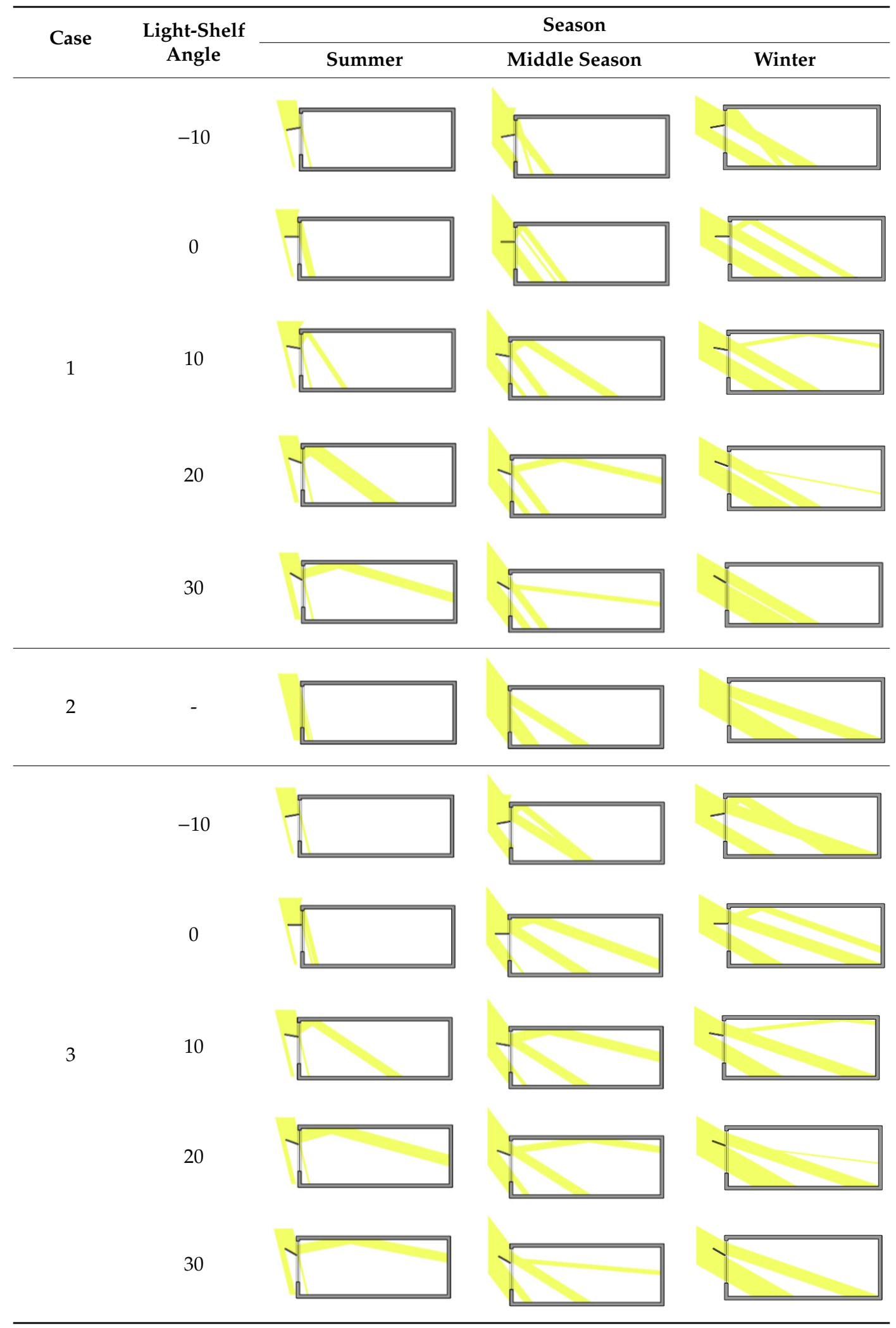

\subsection{Discussion}

This study proposed the use of prism sheets as a way to improve the daylighting performance of external light shelves and analyzed the lighting energy consumption and indoor light uniformity to 
evaluate the sheets' performance. The following is a discussion based on the results of the performance evaluation carried out for this study.

First, Cases 1 and 3 (with light shelves) require different optimal angles during summer, mid-season, and winter to save energy and improve indoor illuminance uniformity, and the results show that operating light shelves is advisable. However, additional energy and structural changes may be required to operate the light shelves, which ultimately reduces their efficiency in terms of saving building energy; furthermore, this increases the cost of designing and constructing a movable light shelf, which can lead to economic efficiency problems.

Second, this study derived the lighting energy consumption according to the optimal light-shelf angle for each case, as shown in Figure 8. The results show that Cases 1 and 2 consume the same amount of lighting energy ( $3.985 \mathrm{kWh})$. However, the lighting energy consumption in Case 3 was $3.985 \mathrm{kWh}$ even when the light-shelf angle was fixed at $20^{\circ}$, which is equivalent to the lighting energy consumption in Case 1 at the optimal angle, enabling an energy saving of $2.9 \%$ when the energy required for operation is taken into account. This demonstrates the improvement of daylighting performance and the effectiveness of applying a prism sheet. Previous studies of light shelves [11-16,18-20] mentioned the need for movable light shelves to improve daylighting performance and save lighting energy; however, this study produced valid results in improving daylighting performance without operating or moving the light shelf.

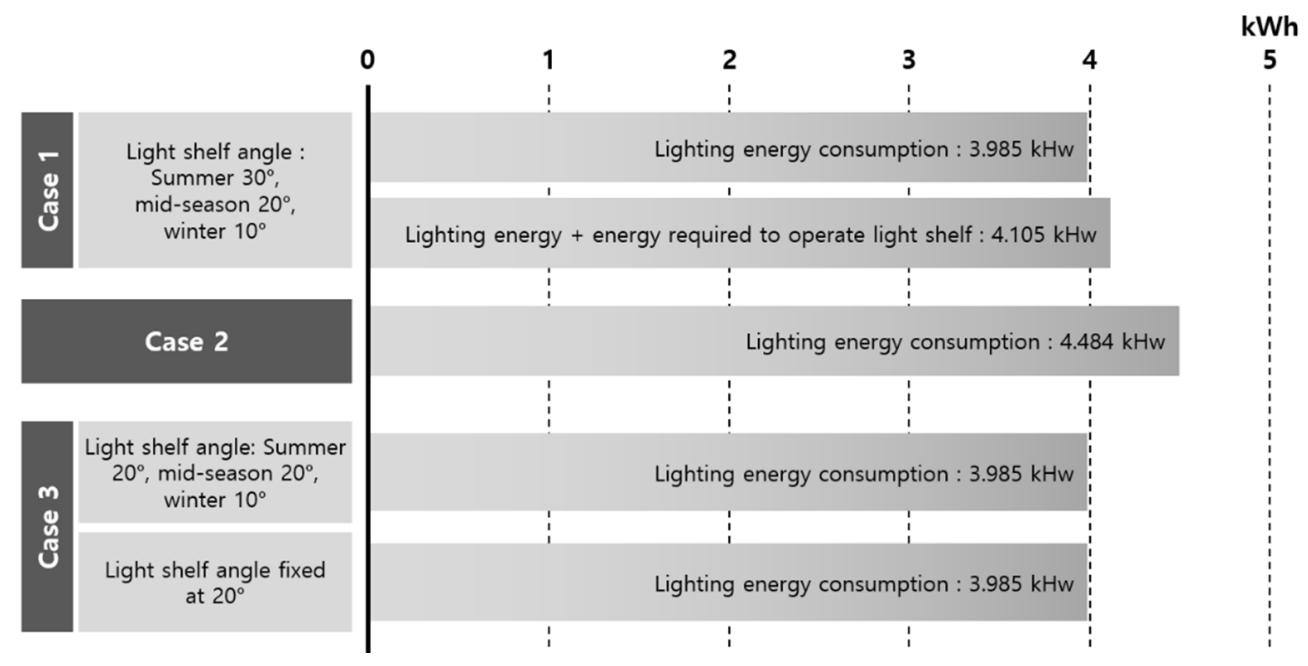

Figure 8. Energy consumption by case.

Third, installing light shelves during winter actually increases the consumption of building energy by blocking solar radiation entering the room [15]. Attaching a prism sheet to the glass surface of a window is also unsuitable for saving building energy, including cooling energy, because it blocks some of the solar radiation entering the room. In this regard, Case 3 (light shelf with prism sheet) may have difficulty saving building energy. Thus, this study proposes the use of detachable prism sheets that can be removed during winter. This is because removing the prism sheet during winter does not increase the lighting energy consumption, nor does it significantly reduce the uniformity of indoor illuminance.

In summary, applying light shelves with detachable prism sheets can not only save building energy but also improve indoor light uniformity.

\section{Conclusions}

This study proposed the use of prism sheets to improve the daylighting performance of light shelves and evaluated the performance according to whether prism sheets were applied and the angle of the light shelf. The main findings are summarized below. 
First, the optimal angles for Case 1 (external light shelf with no prism sheet) to save lighting energy and improve indoor light uniformity during summer, mid-season, and winter were 30, 20, and $10^{\circ}$, respectively. Considering this, Case 1 requires a means of changing the light-shelf angle. Although movable-type external light shelves can improve daylighting performance by responding to external environments such as the solar altitude, the use of additional energy to move the light shelf may reduce the impact in terms of saving building energy. Adding a driving unit to operate or move the light shelf will also lead to complex structures and maintenance difficulties.

Second, Case 2 (window with a prism sheet attached $1.8 \mathrm{~m}$ above the floor) is similar to a light shelf because it can introduce external natural light deep into the room through refraction. However, Case 2 shows an 11.1\% increase in lighting energy consumption and a 19.5\% decrease in uniformity of illuminance compared to Case 1, so simply applying a prism sheet is not suitable for improving the daylighting performance.

Third, the optimal angles for Case 3 (external light shelf and window with a prism sheet attached $1.8 \mathrm{~m}$ above the floor) during summer, mid-season, and winter were 20,10 , and $10^{\circ}$, respectively. Therefore, movable-type external light shelves are favorable for saving building energy and improving lighting uniformity. Accordingly, Case 3 does not show as significant a saving in building energy as Case 1 . However, Case 3 (when the light-shelf angle is fixed at $20^{\circ}$ ) saves $2.9 \%$ more energy and improves the uniformity by $4.6 \%$ compared to Case 1 when the energy required for operation and the optimal angle are considered, which proves its effectiveness.

Fourth, attaching a prism sheet during winter may increase heating energy by blocking the solar radiation entering the room, so the optimal specification for Case 3 is to apply a detachable prism sheet. In particular, the lighting energy is the same even when removing the prism sheet during winter, and there is also no significant change in indoor lighting uniformity, so the efficiency of building energy can be maximized by properly attaching and detaching the prism sheet.

This study is significant in terms of proposing and validating methods to increase the daylighting efficiency by simply applying a prism sheet without controlling the light shelf. A limitation of this study is that the performance evaluation only considers limited environmental factors. Therefore, additional studies should be performed based on various specifications of prism sheets and light shelves and multiple outdoor conditions, including solar altitudes and azimuths, external illumination according to time, and geographical conditions.

Author Contributions: H.L. developed the main idea of the current study; H.L. and J.S. performed and interpreted the analysis and wrote the manuscript; J.S. reviewed the paper. All authors have read and approved the final manuscript.

Funding: This work was supported by the National Research Foundation of Korea (NRF) grant funded by the Korean government (MSIT) (No. 2020R1C1C1004704) (No. 2018R1A2B2007165).

Conflicts of Interest: The authors declare no conflict of interest.

\section{References}

1. Choi, W.J.; Joo, H.J.; Park, J.W.; Kim, S.K.; Lee, J.B. Power Generation Performance of Building-Integrated Photovoltaic Systems in a Zero Energy Building. Energies 2019, 12, 2471. [CrossRef]

2. 2017 Renewable Energy Data Book. Available online: https://www.energy.gov/eere/analysis/downloads/ 2017-renewable-energy-data-book (accessed on 18 August 2020).

3. Freewan, A.A. Developing daylight devices matrix with special integration with building design process. Sustain. Cities Soc. 2015, 15, 144-152. [CrossRef]

4. Courret, G.; Scartezzini, J.L.; Francioli, D.; Meyer, J.J. Design and assessment of an anidolic light-duct. Energy Build. 1998, 28, 79-99. [CrossRef]

5. Kim, C.H.; Lee, K.H.; Kim, K.S. Evaluation of Illuminance Measurement Data through Integrated Automated Blinds and LED Dimming Controls in a Full-Scale Mock-up. Energies 2020, 13, 3238. [CrossRef]

6. Jung, W.; Hong, T.; Oh, J.; Kang, H.; Lee, M. Development of a prototype for multi-function smart window by integrating photovoltaic blinds and ventilation system. Build. Environ. 2019, 149, 366-378. [CrossRef] 
7. Seong, Y.B.; Yeo, M.S.; Kim, K.W. Optimized control algorithm for automated venetian blind system considering solar profile variation in buildings. Indoor Built Environ. 2014, 23, 890-914. [CrossRef]

8. Kosutova, K.; van Hooff, T.; Vanderwel, C.; Blocken, B.; Hensen, J. Cross-ventilation in a generic isolated building equipped with louvers: Wind-tunnel experiments and CFD simulations. Build. Environ. 2019, 154, 263-280. [CrossRef]

9. Konis, K.; Lee, E.S. Measured daylighting potential of a static optical louver system under real sun and sky conditions. Build. Environ. 2015, 92,347-359. [CrossRef]

10. Tao, Q.H.; Li, Z.; Zheng, J.; Chen, X. Model of solar diffuse radiation transmission through circular perforated louvers and experimental verification. Energy Build. 2017, 142, 49-55. [CrossRef]

11. Lee, H.; Park, S.; Seo, J. Development and performance evaluation of light shelves using width-adjustable reflectors. Adv. Civ. Eng. 2018, 2018, 2028065. [CrossRef]

12. Lee, H.; Jang, H.I.; Seo, J. A preliminary study on the performance of an awning system with a built-in light shelf. Build. Environ. 2018, 131, 255-263. [CrossRef]

13. Lee, H. Performance evaluation of a light shelf with a solar module based on the solar module attachment area. Build. Environ. 2019, 159, 106161. [CrossRef]

14. Lee, H.; Seo, J.; Choi, C.H. Preliminary Study on the Performance Evaluation of a Light Shelf Based on Reflector Curvature. Energies 2019, 12, 4295. [CrossRef]

15. Kim, K.; Lee, H.; Jang, H.; Park, C.; Choi, C. Energy-saving performance of light shelves under the application of user-awareness technology and light-dimming control. Sustain. Cities Soc. 2019, 44, 582-596. [CrossRef]

16. Lee, H.; Gim, S.H.; Seo, J.; Kim, Y. Study on movable light-shelf system with location-awareness technology for lighting energy saving. Indoor Built Environ. 2017, 26, 796-812. [CrossRef]

17. Lee, H.; Kim, K.; Seo, J.; Kim, Y. Effectiveness of a perforated light shelf for energy saving. Energy Build. 2017, 144, 144-151. [CrossRef]

18. Warrier, G.A.; Raphael, B. Performance evaluation of light shelves. Energy Build. 2017, 140, 19-27. [CrossRef]

19. Moazzeni, M.H.; Ghiabaklou, Z. Investigating the influence of light shelf geometry parameters on daylight performance and visual comfort, a case study of educational space in Tehran, Iran. Buildings 2016, 6, 26. [CrossRef]

20. Meresi, A. Evaluating daylight performance of light shelves combined with external blinds in south-facing classrooms in Athens, Greece. Energy Build. 2016, 116, 190-205. [CrossRef]

21. Kim, S.E.; Lee, J.Y.; Shin, M.H.; Kim, H.J.; Kim, Y.J. Integration of prism sheet on quantum dot film with bridge patterns to enhance luminance of LED backlight unit. IEEE Trans. Electron Devices 2017, 64, 1153-1160. [CrossRef]

22. Illuminating Engineering Society. The Lighting Handbook, 10th ed.; Illuminating Engineering Society (IES): New York, NY, USA, 2011.

23. ISZ 9110:2010. Recommended Levels of Illumination; Japanese Industrial Standards Committee: Tokyo, Japan, 2010.

24. KSA 3011-2013. Recommended Levels of Illumination; The Korean Standards Association (KSA): Seoul, Korea, 1998.

25. Lee, H.; Kim, S.; Seo, J. Evaluation of a light shelf based on energy consumption for lighting and air conditioning. Indoor Built Environ. 2018, 27, 1405-1414. [CrossRef]

(C) 2020 by the authors. Licensee MDPI, Basel, Switzerland. This article is an open access article distributed under the terms and conditions of the Creative Commons Attribution (CC BY) license (http://creativecommons.org/licenses/by/4.0/). 